\title{
Teachers' Professional Development for the Technology-Enhanced Classroom in the School of Tomorrow
}

\author{
HENRIK HANSSON \\ Stockholm University, Sweden
}

\begin{abstract}
This article discusses the following general questions: (1) what is the role of the teacher in the technology enhanced classroom; and (2) how are teachers prepared for the use of new technology in the classroom? The answers will differ among European countries due to, among other reasons, resources, national initiatives and available infrastructure. The overall goal of using technology in education also needs to be clarified. Is the driving force primarily of an economic nature to make education cheaper? Is the overall goal rather to improve the quality of learning? Is it about increasing student experiences? Is it about attracting more students? Does it have to do with increasing the prestige of teachers? Is it introduced in order to increase flexibility in time, place and organisation of learning? Or is it something else? This article is based on results from two European Union projects, Ewatch and Schoolforesight, as well as innovative ideas and examples of teacher training and development. The European Union project E-watch investigated national policies for e-learning in Europe; the Schoolforesight project included among other activities an essay contest about students' visions of the future school. A study of teachers' visions of the future school was also conducted. No definite answers to the above questions are given, but a number of suggestions, opportunities and inspirational ideas are presented on how to organise the technology enhanced classroom and teachers' professional development.
\end{abstract}

\section{Introduction}

The school of tomorrow is a concern for the whole of society. Moving into an increasingly knowledge-based society makes a skilled labour force the most important competitive advantage for a company, region or country. Jobs are moving out from Europe - not only jobs in the form of traditional industrial work, but also in the form of intellectual work such as design, service and support. India and China, as well as Russia, are fast-growing economies, expected not only to engage in low-level information technology production and services but also to lead the development in the future (The Economist, 2004a-h). Europe has a comparatively older population and needs to focus on updating labour force skills and to build systems for lifelong flexible learning in order to maintain and increase living standards. The European Union (EU) has been investing heavily in this area. School standards play an important role in this process. The EU 5th and 6th framework programmes targeted among other areas the 'School of tomorrow'. The total budget was 14,960 million euros for the activities in the 5th Framework programme of the European Community for research, technological development and demonstration activities, 1998-2002 (http:/ / www.cordis.lu/fp5/src/budget.htm).

In order to design the school of tomorrow one needs to have a vision, a goal. A summary of visions expressed by politicians, students and teachers is presented initially in this article based on two comparative European studies by Hansson \& Holmberg (2003) and Hansson \& Hall (2005). In some cases the visions are converging; in other cases they are different and conflicting goals are uncovered. There is a need for a broad societal debate on the following issues: What is the ultimate 
aim of education? Why? How do we achieve these goals best? These issues are too important to reserve for politicians to deal with alone. This article includes a discussion of teacher opportunities enabled by technology and how to boost teachers' professional development in a cheap, fast and efficient way, while keeping high quality standards.

\section{Information Technology in Education: the perspective of politicians}

The visions of politicians in Europe as expressed in national policies for implementation of information technology in education were investigated by Hansson \& Holmberg (2003). In total 30 countries were studied: Belgium, Denmark, Germany, Greece, Spain, France, Ireland, Italy, Luxembourg, the Netherlands, Austria, Portugal, Finland, Sweden, the United Kingdom, Iceland, Lichtenstein, Norway, Bulgaria, the Czech Republic, Estonia, Latvia, Lithuania, Hungary, Poland, Romania, Slovenia, Slovakia, Cyprus and Malta. One principal question was posed when studying the documents: What are the main aims for implementing information technology in education?

Common motives were: increased teacher skills, increased educational quality, access for all, and increased international cooperation. But this was not explicit in all policies. The national aims were structured into three overall categories: 'To increase ...', 'To protect ...', and 'To change ...'. The increase category was by far the most common. It simply means more of something in the existing system, not critically rethinking or evaluating the current state of affairs. The 'increase' category includes: more computers, updating of computers, more Internet connections, faster Internet connections, increased access for special groups (like the disabled, people in rural areas, old people, etc.), or for some countries, like Sweden, a policy of 'access for all'. These aims are focused on technology and infrastructure. However, in a deeper sense, access is not only about access to computers and the Internet. One also needs to know how to handle the technology and, in addition, there might be language barriers such as the fact that most information available in software and on the Internet is not in the mother tongue and therefore excludes many people because it is inaccessible. Further discussions about language issues related to technology are to be found in Hansson \& Van de Bunt-Kokhuis (2004).

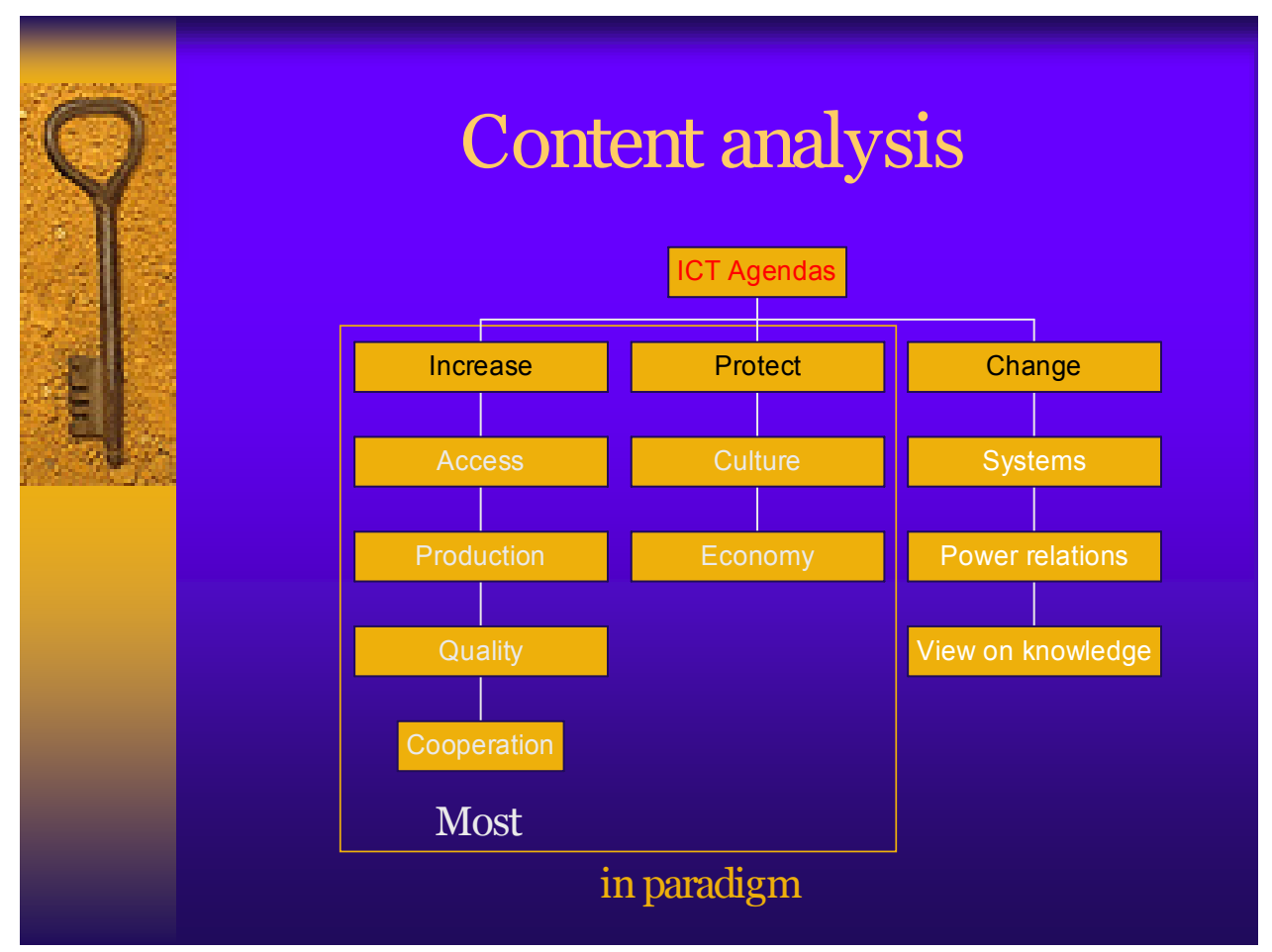

Figure 1. ICT in education. Political aims of increasing different technical aspects. 
A second set of aims was less focused on technology and more on communication. Information technology in this perspective is a tool for cooperation and partnership in various ways. The goals are: more cooperation between schools and the wider society, more international cooperation, better national integration, and more public and private partnerships. Another aspect stressed in many policy documents was increased quality. Increasing quality in the following areas was highlighted: teacher skills, management, educational quality, creativity and innovation.

Most country policies were about increasing something, as mentioned above, but no country mentioned all aspects listed; some only stated one or two goals. Another quite different category was policies not about increasing but rather protecting something which was in danger of disappearing due to information technology and globalisation. In the protect category there were polices about protecting the national language, history and general culture on the one hand, and on the other, explicit actions aimed at protecting national living standards and the economy.

Few countries (in fact only two of the 30) had policies that stressed the need for radical change. However, many aspects of society need to be organised in a fundamentally different way, because the world of today and tomorrow is and will be totally different from the society of yesterday due to the effects of information technology and globalisation. Therefore, there is a need to change the whole education system, the view on knowledge and the power relations between teacher and student.

To summarise, Figure 1 shows politicians' aims for information technology in education in different categories: increasing, protecting and totally changing the education paradigm.

\section{Students' and Teachers' Visions}

How shall we design the school of tomorrow? What is possible? What is desired? Some tentative answers addressing these questions are discussed in this article based on students' visions as expressed in an essay competition, 'School 2020', conducted in five countries, and interviews with teachers about their hopes and fears for the future school. The essay contest was done in the context of the EU project Schoolforesight, with partners in Bulgaria, Estonia, Greece, Rumania, the Czech Republic and Sweden. The students' task was to write an essay about the school in 2020. First, a national contest was held and this was administered by Ellinogermaniki Agogi in Greece, S.C. IPA S.A. in Rumania, the Centre for Prospective Studies, the Technical University of Sofia in Bulgaria, Alfa Omega Communications in Estonia and Gymnasium F.X. Saldy in the Czech Republic. The three best essays were thereafter entered for an international prize.

In general there is a great optimism among innovators in education projects and among students about the future school. The use of information and communication technologies in school is highly appreciated by students and they have great positive expectations of the future school and its potential. The most important aspect in the student essays was the stress on and need for an interesting, encouraging and motivating school, providing relevant knowledge and a good atmosphere between students and teachers. The school visions could be categorised into three groups: 'The School as a Big Arena', 'The Virtual School' and 'The Technology Enhanced Classroom'. In addition to these radically different types of schools, one could add 'The Ubiquitous Learning Environment' based on the development of wireless technology and an increasingly mobile society.

\section{The Future School: students' perspectives}

It was surprising to find out that the essays first and foremost focused on meaningful and motivating activities, basic values, and relations with friends and teachers. The so-called 'social capital' played an important role in the essays (Putnam, 2001). Social capital is about trust, social relations and networks, aspects that are deemed essential in our society and increasingly so. In fact, many of the visions for the future related to this non-technological field could be implemented already if the students' voices were heard. The technological aspect was a second theme. Before talking more about technology and its impact on school, its organisation and the changing social relations, one needs to remember the students' principal point - school activities must be 
interesting, challenging, exciting, relevant and meaningful from the students' point of view; if not, all investments in technology in schools will be wasted.

Another surprise when reading the essays was that some student opinions could be compared to workers' opinions about a future paradise - one essay started as follows: 'in the future most pupils wish there was no school at all' - or stated that they wanted to start at $10 \mathrm{a} . \mathrm{m}$. and have Fridays off. Obviously students of today have mixed feelings about the current school. It is not selfevident that school must lock students up during most hours of the day for years and years. There are reasons for keeping them there, but also opportunities for a more flexible learning life in the same way as working life is developing.

Student visions, as expressed in the essays, could be grouped into three categories: 'The Arena School', 'The Virtual School' and 'The Technology Enhanced Classroom'. A fourth complementary category could be added to these scenarios, 'The Ubiquitous Learning Mode'. The Arena school is characterised as a large, modern, high-tech, all-purpose school building. The Arena school fulfils all pupil needs, physical, social, technical and educational. There is a cinema, highquality restaurants and cafés, laboratories, science and computer equipment and sports facilities. In this large school complex one meets friends and teachers and other staff members face to face. It is fun and exciting. In fact it seems to be the centre of life and every day is a new adventure. Also leisure hours are being spent in these facilities. Most essays expressed an Arena vision. There were also some students who expressed doubts about a highly technical school environment, and one student even suggested a total rejection of it, a kind of 'back to nature' revolt in the spirit of Jean Jacques Rousseau (1993).

'The Virtual School' is the total opposite vision. In this scenario a physical school does not exist. The school enters the home. From home the student interacts face to face (or maybe better: 'e-face to e-face') with schoolmates and the teacher via large screens on the wall. There is no commuting, no stress in the morning; in fact one can take part in the lessons from the breakfast table. The student who expressed this vision stressed the importance of synchronous visual contact in order to 'control' the children, who otherwise would try to get away with things or do other activities. The school day was perceived as a 'normal' school day, but with all involved participating from a distance via transparent technology; 'they appear to be in the same room'. Most students mentioned the importance of physical activity, especially since computer and screen interaction is a passive mode. The student who drew up the vision about the virtual school suggested that the real-life interactions took place after home-based lessons. All students gather in the afternoon and evening in the local village or town in order to interact socially and do sports activities. This approach is a kind of distance education, but focuses on real-time dialogues and the use of audiovisual technology available to all in their private homes. The expensive school arena is not needed, but instead investments have to be made in private homes. Salmon $(2000,2002)$ among others has stressed the importance of dialogues in online courses as opposed to ready-made content packages, but the technology in distance education so far has been restricted mainly to text chat and asynchronous text via emails or forums. The students envision a technology that enables a richer dialogue with face and body language in addition to voice and integration of persons acting from multiple locations.

'The Technology Enhanced Classroom' was another common vision among students. It is simply the traditional classroom reinforced with technology: computers and Internet that enable more independent studies, international cooperation and access to information from a large variety of sources. Since some students who wrote the essays were participating from schools that seem to lack computers for student use, it was a great vision to just get access to a computer. In a European school context the resources are very different between countries - in Sweden, for instance, all schools are equipped with computers and Internet access. But some people think that it will not be desktop or laptop computers in the future, but instead more developed mobile phones, so-called 'smart phones', that include all types of information and communication technologies. The student use of mobile phones, which already haVE a wide range of extra functions such as cameras, SMS, Internet access etc., is such a problem in Swedish schools that national politicians discuss this issue and are considering legal means for teachers to confiscate them in order to restore discipline. Sweden invests the most in the world in public education, but according to recent studies has severe problems with discipline in the classroom (Swedish National Agency for Education, 2004). 
The student essays uncovered three distinct different visions of the future school: the Arena School, the Virtual School and the Technology Enhanced Classroom. A fourth plausible scenario of the future school could be: 'The Ubiquitous Learning Mode'. This vision is learning via the availability of information and communication opportunities everywhere. The availability is there all the time via wireless high-speed broadband networks. We can imagine small portable devices, but increasingly the needed equipment is built into the environment itself: in cars, in trains, at airports, hotels, restaurants etc. In Sweden, for instance, wireless Internet is already available at a certain hamburger chain covering the whole country. This means that 'the classroom', if that is the suitable term, can be anywhere and also that learning can take place in a lifelong and autonomous fashion in a totally new way. Even the most remote areas can now be reached via satellite and the infrastructure is quickly improving. 'The digital generation' that knows no world without computers will be used to this 'language and culture' in a totally different way than the generation born before the computer age. Marc Prensky (2001) even suggests that their brains are structured differently because of their intense use of videogames and because the logics in the digital world completely differ from the logics in the print world.

\section{The Future School: teachers' perspectives}

A group of teachers from England, Greece, Italy, Portugal, Spain and Sweden was asked to write down keywords signifying the future school and to explain and discuss these keywords. The keywords are categorised and abstracted into the general concepts shown in Table I. As we can see, there is a concern among teachers that media and technology development might create lazy and passive students with problems focusing on deep learning. Market mechanisms will force schools to be more adapted to work life and less to 'academic' learning. Less funding for education and lower teacher salaries in public systems is another perceived threat.

On the other hand, some teachers were more optimistic (and in many cases one individual suggested both scenarios). The promises for the future, according to the teachers, were the ability to tailor schools more to individual needs, to use the creativity and producer tools to create more meaningful learning activities and to use media in an entertaining and engaging way with a learning content. The risks and promises with new technology in education are discussed by Burbules \& Callister (2000) among others; they emphasise the need for students to develop critical thinking when using Internet material.

\begin{tabular}{ll}
\hline Hopes & Fears \\
\hline Active students & Lazy students \\
Creators & Consumers \\
Entertainment: learning & Entertainment: stupidity \\
Focused: Homo Sapiens & Unable to focus: 'Homo Zap'iens' \\
Individual needs & Mass approach \\
Humanistic & Commercial \\
\hline
\end{tabular}

Table I. School of tomorrow: teachers' hopes and fears.

One teacher suggested that the future school could be summarised with a number of words starting with 'inter':

- Interconnectivity. Everything is connected: school and work life, school and home; media and communication channels: TV, phones and computers, etc. See Pavlik \& McIntosh (2004) on media convergence.

- Interactivity between students and students, students and teachers, teachers and parents, etc.

- Internet. More and more of our communication and information is carried by the Internet; for schools: homework, digital libraries and schedules, to mention just some applications.

- International. Our world is increasingly international; locally, there are more immigrants and people with different cultural background to be found in the local schools, and our ability and need to interact with the wider world is important in this context. 
- Interdependence. In this increasingly international world we are more and more dependent on each other, and events even in remote areas can quickly affect our lives. It is no longer possible to handle alone such issues as the environment, security and health.

- Interdisciplinary. The merging of old scientific disciplines with new fields of knowledge is constantly taking place. Problem solving is in focus and in order to solve a problem today one needs skills and knowledge from a wide variety of disciplines.

\section{Teachers' Professional Development}

Teaching and learning using information and communication technology can be organised in several different ways depending on purpose and infrastructure. Teachers will use the technology according to the students' needs and their own preference. In some cases technology will be given added value in terms of better understanding of complex concepts or a more flexible interaction and coordination of activities. Table II displays four structurally diverse ways of adopting technology in education. These arrangements are also connected to learning theory and teacher preferences on how education should be conducted. Some teachers will only select one mode, while others will combine and mix approaches according to purpose, tasks and composition of the student group.

\begin{tabular}{lll}
\hline & Same place & Different place \\
\hline Same time & 1. Technology-supported teaching & 3. Synchronous communication \\
& - Demonstrations & - Videoconference \\
& - Visual presentations & - Chat \\
& & - IP telephone \\
& & - Whiteboard \\
Different time & 2. Technology-supported learning & - Audio chat \\
& - Self-studies & - Esynchronous communication \\
& - Multimedia & - E-board \\
& & - Audio forum \\
\hline
\end{tabular}

Table II. Information and communication technology related to time and place.

In the first case technology is used in the traditional classroom, with both teacher and students present at the same time. This enables face-to-face interactions and a familiar situation for both students and teacher. In fact this is the situation with the widest 'broadband' - most signals, cues and information are at hand. All other situations limit signals and feedback cues, such as the whole body language of all involved, face language, eye movements, multiple voices, hyper feedback, multiple computer and projector screens and additional white boards, physical instruments, etc. In the 'same time and same place' situation teacher or students can use technology to illustrate, demonstrate and simulate concepts, perform experiments, add visual information to an oral lecture and the like.

Computers, projector and the Internet in the classroom accompanying a 'classic' oral lecture may be the most common use of technology in education. In fact, even conferences about 'online learning' are mainly organised as oral face-to-face lectures to a bigger audience present in the same room. Today PowerPoint slides and oral speech are so dominant in conferences that it may hinder creativity, interactivity, spontaneity and other ways of 'telling the story'. Computer projector-led lectures are increasingly becoming popular at universities, but the introduction of the technology has been slow. The main factor is that projectors are still expensive, whereas computers are not and the older teacher generation does not know how to produce PowerPoint presentations. We may call them the 'overhead generation', but many do not even construct overheads for their lectures, in contrast to the new 'digital generation', who, without special education, quickly learn how to construct PowerPoint presentations due to computer experience from their daily lives.

To learn how to make a PowerPoint presentation even for an 'overhead generation' person would not take more than half a day. The PowerPoint slide presentations will become much more elaborate in the future and there might be other programmes doing the task better and more 
efficiently. Interplay with contents from the Internet will be more and more integrated, as well as interplay with other people at a distance.

The second case, 'Technology supported learning' (Table II), is a situation where we may have expensive technical equipment in a place open for students to conduct self-study at their chosen time. It could be a flight simulator, a special computer lab or computer surgery equipment which is available for students and their independent learning without the supervision of the teacher. A number of learning centres have been set up in Sweden to enable people without computers, video conferencing facilities and the Internet to conduct distance education. But since computers are becoming cheaper and cheaper and the Internet increasingly accessed easily and inexpensively everywhere, basic computer equipment is moving into private homes. There is nevertheless some technology that is either too expensive to buy for home studies or requires too much space to house in a private room. However, a function not to be overlooked is that learning centres are social meeting places. Even if people have computers at home they often do not have an ergonomic workplace or enough space to interact with friends. Also, to leave home and start studying in another place may structure the private and study life more efficiently. The game palaces are an example of this social phenomenon. Even if players of digital games can conduct their activities alone at home and interact via the Internet, they often prefer to meet physically and play together in a special game hall.

The third arrangement, 'Synchronous communication' (Table II), refers to the situation when teacher and students are separated in space but interact at the same time at a distance. This can be done audio-visually using videoconferencing (increasingly via the Internet), text via chat, voice via ip (Internet protocol) or 'traditional' telephone meetings. The technology itself does not determine the pedagogical approach. For instance, an audiovisual interaction can be a traditional lecture sent in television format or a session where students present and discuss their work. The first model is less interactive and may be running the risk of being a boring 'talking head' session, but of course a lecture could also be structured to invite interaction.

It is important to notice the great difference between classroom teaching and audiovisual distance lecturing because of the reduced cues for feedback - how are the students receiving the message and how can the students intervene? The telephone conference is an underestimated means of teaching and supervising. It enables fast and clear interaction and it is a cheap and reliable technology. Increasingly, telephone calls are made for free worldwide using, for instance, Skype or Groove software. Another way of interacting synchronously is by using a common workspace online - slides, whiteboard, etc., with or without faces (images still or moving) and with or without voice. Text can be used in a chat forum, but it is more time-consuming than voice interaction. The advantage is, of course, that the text dialogue is saved and can be used to recall the session. This use of technology in education focuses on dialogue and may be contrasted to the previous arrangement, case two, where the dialogue between teacher and student played no role at all, the focus rather being on the interaction between the student and the technology.

The fourth possibility, 'Asynchronous communication' (Table II), is also focused on the teaching dialogue between teachers and students. This way of using technology enables teacher and students to be totally free, when it comes to where to interact and when to interact. This creates enormous freedom, but also problems of structuring and solving problems efficiently. Often an asynchronous teaching mode is said to be independent of time and space, but nothing can be more wrong. We are very much dependent on place, but we can freely choose where to work. We always need to be somewhere and this environment poses limitations: what about Internet connections, computer availability, printing possibilities and social interaction at home? On the bus? At the restaurant? Abroad? Etc . We are not independent of time either; in fact we need much more time when interacting asynchronously compared to spoken face-to-face interactions. Log in and read and write takes 7-10 times longer than listening and speaking. Also, many more interactions may occur during a day. One teacher had 700 mails from students each day and not even time to sort them into categories. The so-called freedom of asynchronous teaching and learning may be a burnout situation for the teacher who can be reached everywhere and at any time. The solution is to distance students and give clear instructions about when feedback can be expected; for instance, only to expect teacher responses on Fridays, other days being occupied with other activities. 
With this in mind there are many opportunities for structuring information technology for teaching and learning. There is a need for a clear and informative 'communication contract' between teacher and student, indicating the basics of the online communication: When? How? How much? About what? It is also important to make clear the responsibilities when online communication fails - who needs to take the initiative in different situations: student or teacher? The more explicit this is, the better the working situation for the teacher and the learning situation for the student. However, these are often implicit and non-regulated issues which create chaos, misunderstanding and even total breakdown.

Teachers' professional development for using technology in education will vary across time and space as well. Some countries in Europe have strong national initiatives and others leave teachers on their own to take care of their competence development. There are also generation gaps between the 'pre-overhead generation', the 'overhead generation' and the 'digital generation'. There might be less of a problem with future generations because they have grown up with and are used to computers and the Internet. But if our present teachers do not use technology efficiently in the classroom, this will have a negative effect on the next generation as well. Studies have shown that young people have a positive attitude towards new technologies, but are disappointed in the way they are used in schools. Therefore, massive and rapid teacher education programmes are of crucial importance. Many initiatives have already been implemented and have had positive effects. Still, computers and the Internet in universities and schools may primarily be used for administration of students rather than for teaching and learning.

How can teachers gain the required knowledge? There is a considerable portion of informal learning taking place, slowly increasing the general digital competence: for example, students teaching teachers, teachers' children teaching their parents. Also, teachers need to carry out a number of daily activities outside school using computers and the Internet: bank account administration, travel booking, media consumption, etc. These changes and informal learning opportunities will change teachers' behaviour also in the class room.

There are also traditional courses available to teachers, a few hours each week or full days learning a particular IT skill. There a number of studies showing that the uptake of new innovations follows a trend: first, a small group of pioneers, then later the majority and finally the laggards (some will never change). Aviram (2004) has suggested the following categorisation of teachers and staff in schools:

- The conservatives. Technology in education is fundamentally bad and destructive. Nothing is improved by technology in education, but rather it makes quality lower. Back to basics and classical studies.

- The technocrats. We place computers and the Internet in the classrooms and see what happens. Assuming only positive effects.

- The moderates/reformists. Well, there might be some positive effects in education using technology. We try to improve the curriculum and teaching with the add-on of technology.

- The radicals/revolutionaries. Technology will fundamentally change our culture, our relations and education. We need to change everything - a total paradigm shift is needed (Kuhn, 1996). Schools and universities may not exist in the way we know them today; maybe they are not even needed, when people independently can access and learn virtually everything on their own without formal structures.

Of course we have to deal with teacher optimists willing to change and learn new technologies, but also acknowledge the conservative group who do not want to change. As we saw in the student visions of the future school, 'motivation' is the number one factor for learning and this applies also to teachers' learning. If they are not motivated, all resources spent are wasted (Illeris, 2003).

\section{Gender and Information Technology}

There are a lot of studies about the differences in ways of communication between males and females. Supposedly, the way of speaking about new technology for learning is a predominately 'male language' with technical terms and this unnecessarily excludes females. The trial and error approach of learning that often characterises early phases of technology development and implementation are also reported to be more of a male style of learning. There are other studies 
reporting gender differences in Internet network activities. It can also be stated that once females have been introduced to and learned the new technologies - and found meaningful and important applications - they often surpass the males in using them.

\section{Touring Technical Education Theatres (T3)}

In addition to informal learning in daily life, which slowly and incrementally will increase teacher competence, and the traditional formal teacher training courses, I would like to suggest another way of addressing this mass education need, a quality approach which is rapid and fun: Touring Technical Education Theatres (T3). The idea is to combine a number of pedagogically sound ideas with a technical and administrative structure, thus creating a paradigm shift among teachers in a quick and motivating way.

Figure 2 illustrates the set-up. There are three different phases: (1) Pre-phase, (2) Kick-start session face to face, and (3) Post-phase. The first phase is online (or at a distance using ordinary mail/fax) and this is where (a) marketing takes place: information about the activity and its goal and structure, (b) a schedule is presented and the individual chooses a suitable day for the face-toface kick-start session, and (c) a self-assessment questionnaire investigates each individual's preknowledge regarding skills with IT in education, and their interest in learning a number of new skills.

\section{T3 - Touring Technical Education Theatres}

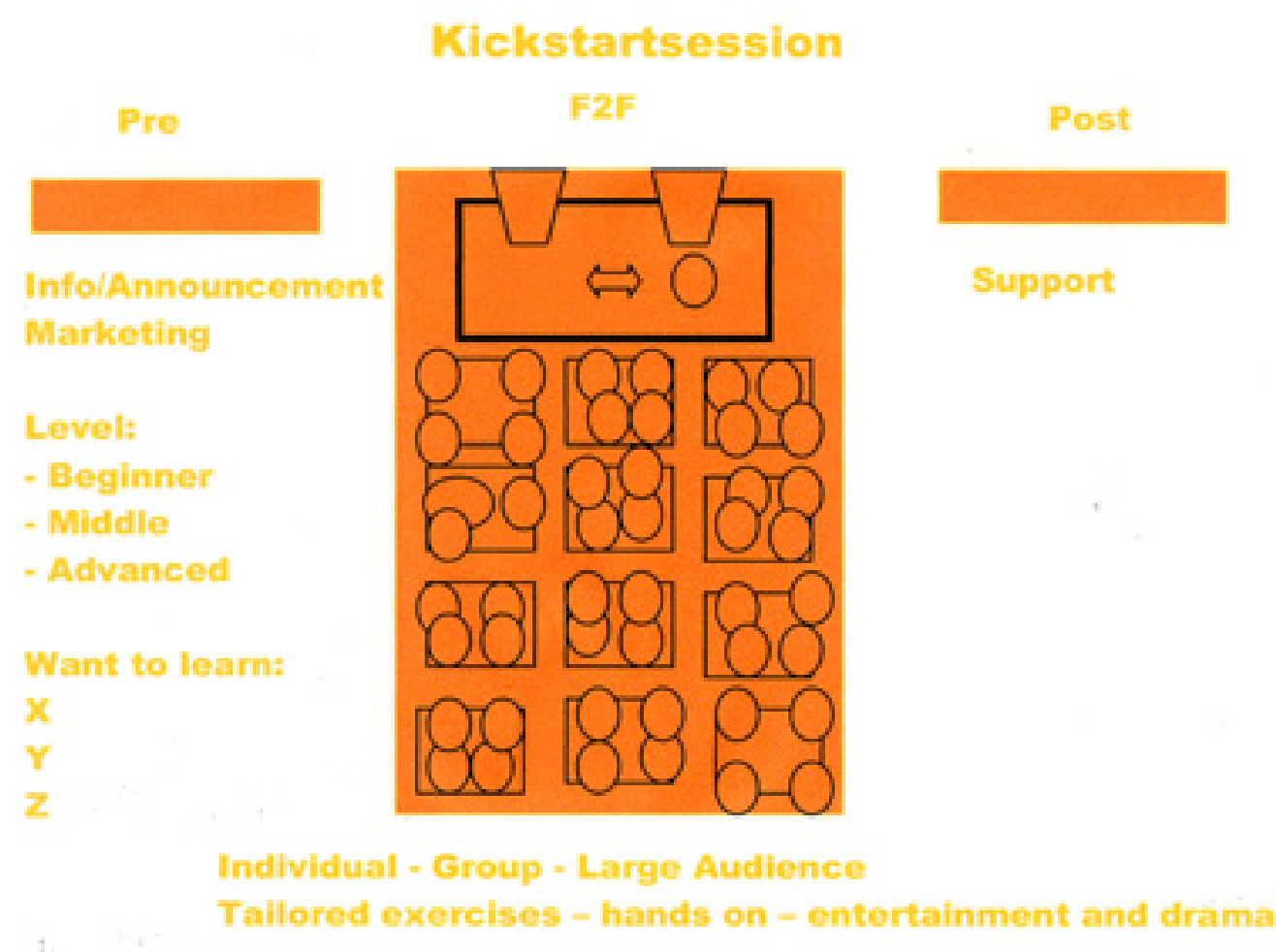

Figure 2. T3 Touring Technical Education Theatres.

The online questionnaire provides learner profiles of each participant well in advance of the actual meeting and is the basis for selecting exercises and demonstrations relevant to each individual and also a way of categorising the learners in a computer game style: beginners, average and advanced users. These activities will match the level of skills. The beginners as well as the advanced will get activities according to their acquired level. The importance of building on existing pre-knowledge and not to create a learning situation characterised by too low or too high levels of complexity is 
stressed by educational theorists such as Piaget, Vygotsky, Gadamer and Dewey. The knowledge acquired by the online questionnaire for the T3 teachers and organisers about the learners' preknowledge before the session is of great importance in making the one-day session as effective as possible.

The actual kick-start session face to face is motivated by a number of factors. A pure online course would probably not work well for the beginners and more than one day would cost too much in time and resources. Participants may not only be teachers but all involved in education: librarians, administrators, managers, technicians, etc. The impact is greater if all staff in a school get the same experiences and share a 'culture'; especially the management is needed in order to achieve real change in a school. The traditional individual teacher's courses may inspire early adopters, but they may not get any support for change among other staff and management when they return to teaching in class. These people are in the risk zone of burnout since they often do the teaching plus a lot more: introducing and using technology, building up local infrastructure, etc.

The kick-start session is a happening, a fun activity such as a theatre performance or a rock concert. Why do musicians fill large halls with audiences several years before the actual three-hour concert? And why are people are willing to pay for it? (I mean that there is something to be learned from this approach; education is not as popular and is given in a dull and boring format when learning meaningful things can be as rewarding and exciting as a rock concert -even more so). In contrast, further education is in general boring; less people are interested and very few are prepared to pay or invest their time on it. The kick-start session borrows some of the drama from concerts and theatre. The initial act is a drama with expert users ('stars') showing in a playful, intensive and surprising way what one can do with technology in education, using all stage set-ups with sound, light and properties. The goal is to give the audience an 'aha!' experience and inspire them to do the same (that is, learn how to do it). The experts are few, therefore they may be needed 'on tour' one-day visits at different schools, which makes the programme efficient. Preferably a 'star' (expert) or a novice can be recruited locally from each school and be part of the 'play'. That would make possible the needed local connection and link to the audience.

When the 'expert play', showing what it is possible, has ended, it is the audience's turn to be active in teams. It is important that the session is not only about passive viewing, but also about actual hands-on learning in the spirit of Dewey: 'learning by doing'. The teams have been created already, based on online information. There can be beginner teams, advanced teams or mixed teams. Preferably the teams are multi-professional, involving teachers, librarians, technicians, administrators. The teams will work using computers and the Internet to solve pre-defined tasks according to the preferences they expressed in their online assessment. Most problems can be solved in teams locally, and other questions mailed to the expert group who would answer immediately via all computers and/or on a large screen. In this way supervision of hundreds of people will run smoothly since there are only a few questions, but asked over and over again. A few people can disseminate their knowledge to large groups of people in a short time. Another benefit of the hands-on teamwork is that it can create communities of people sharing the same experiences and after the session an informal network can continue to exist where the team members solve problems together. A team of 4-6 will have another 25 people, relatives, friends, colleagues, etc., who they can consult as a resource pool. Also, it important to stress that educational planning, teaching and evaluation based on teams have many advantages over the lonely individual teacher in the classroom. A local team of school staff will have more impact on changing teaching and routines than an individual educated alone with no one with whom to share experiences and inspiration.

The session day is a mix of 'expert play' for a large audience, teamwork and individual activities. The idea is to inspire and 'kick-start' learners to learn themselves. At the end of the faceto-face day, in addition, the participants have accomplished something concrete for themselves, a digital product to improve their course or teaching. Social interaction, personal relations and empathy is stressed during the session day to make people feel secure, have fun and build trust and confidence, learning to know each other in the process. The cultural aspect, which is shared experiences, norms and values in a group, is of great importance, as we can learn from anthropologists such as Roger Keesing \& Andrew Strathern (1998). 
After the inspiration day, the learners are free to use online support regarding all questions arising from implementation in practice. In this way large groups of learning teachers can be supported efficiently. The follow-up is important. To keep an open door for dialogue after reflection and during practice enables lifelong learning in a flexible way.

In summary, the technical touring theatre approach would take one day of experts' and teachers' time: would it make a difference?

\section{Conclusions}

Teachers' professional development for using information technology (IT) as education technology (ET) will depend on national policies, which in Europe are very diverse, and on institutional policies which in many cases are lacking or conflict with the national policy. Individual independent learning, formal and informal, will be of importance for each individual teacher. Important also is the responsiveness to new generations of students. The digital generation and their skills and needs will have an impact on the teachers' teaching. Teachers' motivation for using new technology is crucial; it can be stimulated by external means such as innovative national initiatives, preferably developed together with teachers and not a pure top-down approach. Better resources for education in general and higher teacher salaries in particular are also important external motivating factors. Motivation can also be attained by reflecting as a teacher: What is in it for me? How can I improve my teaching using technology? What are the benefits for the students? If the answers are positive, change will occur.

\section{Acknowledgements}

The Schoolforesight partners: Ellinogermaniki Agogi, Greece, S.C. IPA S.A., Rumania; Center for Prospective Studies, Technical University of Sofia, Bulgaria; Alfa Omega Communications, Estonia; Gymnasium F.X. Saldy, Czech Republic; Scott Hall, Institute of International Education, Stockholm Sweden; Carl Holmberg, The Swedish Agency for Flexible Learning; Görel Strömqvist, Institute of International Education, Stockholm, Sweden.

\section{References}

Aviram, R. (2004) Presentation at the EU Science Week in Athens. Symposium related to the EU project Schoolforesight. November.

Burbules, N.C. \& Callister, T.A. (2000) Watch IT: the risks and promises of information technologies for education. Boulder: Westview.

Economist, The (2004a) A World of Work, 13-19 November. Special section, pp. 3-4.

Economist, The (2004b) Men and Machines. Technology and Economics have already Revolutionised Manufacturing. White-Collar Work Will Be Next, 13-19 November. Special section, pp. 5-7.

Economist, The (2004c) A Desperate Embrace. Companies Do Not Always Outsource for the Best of Reasons, 13-19 November. Special section, pp. 7-8.

Economist, The (2004d) The Place to Be. The Global Market for White Collar Work, India Rules Supreme. But Others are Lining Up. 13-19 November. Special section, pp. 8-10.

Economist, The (2004e) Faster, Cheaper, Better. India's Emerging IT Firms are Trying to Beat their Western Rivals on their Home Turf. 13-19 November. Special section, pp. 10-12.

Economist, The (2004f) Into the Unknown. Where Will the Jobs of the Future Come From? 13-19 November. Special section, pp. 12-13.

Economist, The (2004g) Sink or Schwinn. Sourcing from Low-Cost Countries Works Only in Open and Flexible Labour Markets. Europe’s are Neither. 13-19 November. Special section, pp. 14-15.

Economist, The (2004h) A World of Opportunity. Why the Protectionists are Wrong. 13-19 November. Special section, pp. 15-16. http:/ / www.cordis.lu/fp5/ src/budget.htm (accessed 22 April 2004).

Hansson, H. \& Hall, S. (2005) The Future of Schools from a European Union Perspective: selecting, analyzing and disseminating the most innovative approaches towards the school of tomorrow, Policy Futures in Education, 3(1), pp. 30-37. http: / / dx.doi.org/10.2304/pfie.2005.3.1.7 
Hansson, H. \& Holmberg, C. (2003) A European and SwedishPerspective on ICT - policies and strategies in education. National and Institutional Pathways: crossings, blind alleys and uphill slopes, Journal of Systemics, Cybernetics and Informatics, 2(6). http: / / www.iiisci.org/Journal/SCI/ Abstracts.asp?var=\&Previous=ISS3407

Hansson, H. \& Van de Bunt-Kokhuis, S. (2004) E-learning and Language Change - observations, tendencies and reflections, First Monday. www.firstmonday.dk

Illeris, K. (2003) Adult Education as Experienced by Learners, International Journal of Lifelong Education, 22(1), pp. 13-23. http: / / dx.doi.org/10.1080/02601370304827

Keesing, R.M. Strathern, A.J. (1998) Cultural Anthropology: a contemporary perspective. Forth Worth: Harcourt Brace.

Kuhn, T.S. (1996) The Structure of Scientific Revolutions. Chicago: University of Chicago Press.

Pavlik, J. \& McIntosh, S. (2004) Converging Media: an introduction to mass communication. Boston: Allyn \& Bacon.

Prensky, M. (2001) Digital Game-Based Learning. New York and London: McGraw-Hill.

Putnam, R.D. (2001) Bowling Alone: the collapse and revival of American community. London: Simon \& Schuster. Rousseau, Jean-Jacques (1993) Émile [Émile ou léducation: translated by Barbara Foxley]. London: J.M. Dent. Salmon, G. (2000) E-moderating : the key to teaching and learning online. London: Kogan Page.

Salmon, G. (2002) Etivities: the key to active online learning. London: Kogan Page.

Swedish National Agency for Education (2004) PRESSMEDDELANDE 2004-12-09: Mer än varannan 10-12 åring saknar arbetsro i skolan. [More than $50 \%$ of the 10-12 year-old students are disturbed by others when studying]. http:/ / www.skolverket.se/sb/d/203/a/306 (accessed 13 December 2004).

\section{Gender Issues, Resources}

Gender Evaluation Methodology for Internet and ICTs: http:/ /www.apcwomen.org/gem/

GEM is a guide to integrating a gender analysis into evaluations of initiatives that use Information and Communication Technologies (ICTs) for social change (accessed 3 February 2003).

Gender and the Digital Divide Series: http:/ / www.worldbank.org/gender/digitaldivide/

The Gender and the Digital Divide Seminar Series is being sponsored by the Gender and Development and Girls' Education Thematic Groups, and Bridging the Digital Divide through Education Task Force of the World Bank. The series looks at the impact that ICT is having on gender relations and innovative ways that ICT is being used to bridge the digital divide (accessed 3 February 2003).

Gender Disparities in Information Technology. By Lori Gerstein Ramsey.

http://www.womanstown.com/papers/gender_disparities.htm (accessed 3 February 2003).

American Surfers Keep It Simple. By Robyn Greenspan.

http:// cyberatlas.internet.com/big_picture/geographics/article/0,5911_1466661,00.html (accessed 3 February 2003).

Case Study Forum, Gender:

http:/ / www.ecomlink.org/E_incubator/Case_Studies.asp?CategoryID=981 (accessed 3 February 2003)

Gender and Stakeholder Analysis:

http:/ / www.prgaprogram.org/gender.htm (accessed 3 February 2003).

Information and Communication Technologies: a women's agenda:

http:/ / www.enda.sn/synfev/apcfemafr/TICang.html (accessed 3 February 2003).

Women Learning and the New Technologies - 8 March 1999, London ... the obstacles women may encounter in access to new technologies and will explore some of the ways in which ICT can be used to enhance their performance in education, training and employment. 
Delegates will have the opportunity ...

http:/ / www.niace.org.uk/Conferences/Gender/IWD1999.htm (accessed 10 March 2003).

\section{Books and Articles}

Allen, Donna, Rush, Ramona R. \& Kaufman, Susan J. (Eds) (1996) Women Transforming Communications global intersections. London: Sage.

Carter, Kathryn \& Spitzack, Carole (Eds) (1989) Doing Research on Women's Communications: perspectives on theory and method. Norwood: Ablex.

Davidson, Marilyn J. \& Cooper, Cary L. (Eds) (1987) Women and Information Technology. Toronto: John Wiley \& Sons.

Hacker, Sally (1989) Pleasure, Power and Technology. Boston: Unwin Hyman.

Hacker, Sally (1990) Doing it the Hard Way: investigations of gender and technology. Boston: Unwin Hyman.

HENRIK HANSSON has conducted several research projects in technology-based distance education and communication sciences. He was research and development adviser at the Swedish Agency for Distance Education during 1999-2002 and presently is a senior lecturer at the Institute of International Education and Department of Education, the multimedia unit, Stockholm University, Sweden. Current research and development projects include: (1) 'Rural Wings', a large worldwide project aiming to bring the Internet and distance education to rural areas and developing countries; (2) Schoolforesight - designing the school of tomorrow. This is an EU-funded project with partners in Bulgaria, the Czech Republic, Estonia, Greece and Rumania; (3) A Swedish-South African comparative study of e-learning in higher education: reaching marginalised groups with new technology, involving university partners in Johannesburg, Cape Town, Potscheftsroom and Pretoria in South Africa; (4) FILTER: EU-funded special interest group focusing on the Internet filtering of information and the consequences for education and learning. Correspondence: Dr Henrik Hansson, Institute of International Education/Department of Education, University of Stockholm, SE-106 91 Stockholm, Sweden (henrik.hansson@interped.su.se). 